REMARKS

ox

\section{PAROXYSMAL SNEEZING.}

BY SYD.TFI RINGER, M.D., F.R.S., Holme Pmofessor of Clinical Mrolitine, University College, London. AND

WILLIAM MURRELI, M.D., F.R.C.P., Lecturer o: Matteriat Medicit anil Therapeutics, Westminster IIospital, Loulon.

\section{Part I.}

THe frequency with which of lnte years cases have been recorded under the title of "IIay Fever," and similar terms, has attracted attention to a curious and interesting complaint, the very existence of which was not definitely recognised unt il the publication in 1819 of Dr. Jolın Bostock's account of his own symptoms and sufferings. It is true that IIeherden, in lis Commentarii de $\mathrm{Mor}-$ borum Historia et Curatione, speaks of an annually recurring attack of catarrh in certain individuals, but he probably regarded it much in the same light as did Dr. Hlliotson, who, in his Practice of Medicine, spenking of this complaint says:- "I could not tell what to make of it, and I disregarded it entirely, supposing it to be a sort of aguish or hypochondriacal affection, of which those who had little or nothing to do became the sulject." The disorder is of great interest, not only from the mystery which surrounds its earlier history, but from its prevalence in all countries, and the tenacity with which, once having attacked its victim, it clings to the unhappy sufferer during the best years of his life.

The names "hay ferer" and "hay asthma," it must he admitted are unfortunately chosen, for the existence is now very generally recocrnised of a complaint presenting inlentically the same symptoms, but excited by causes other than the presence of pollen in the atmosphere. Bostock, in his second communication, published in 18.2 $\mathrm{x}$, called it the "catarrhus estivus;" whilst Dr. Phoebus, in 186., in his well known monograph on the subject, speaks of it as the "Frühsommer katarrh," or early summer catarrh. The names "summer asthmo" and "summer lironchitis" are also used, but all these coses may be more appropriately classified under the general term, "paroxysmnl sneezing," the unfortunate sufferers being appropriately called "sneezers." The attrcks, whatever may he their exciting cause, may affect only the upper part of the respiratory tract, or they may involve the lungs, or both may suffer. The sneezing paroxysms usually alteruate with or replace the asthmatic troubles, or one of them may preponderate. In both rarieties we meet with cases in which there is itching or irritation of a part or even of the whole of the interior of the nares, or possibly the feeling of discomtort may involve the inner canthus of the eyes or the whole of the eyeball, being accompnnied by reprated and riolent attacks of sneezing and profuse watery discharge from the nose or from the nose and eyes. Again in both forms the irritation may attack the soft palate and pharynx, there being experienced in these parts a feeling of roughness, or as patients often call it, "scrnping." The lungs too may be attacked, not only witlı asthmatic troubles, but by symptoms of bronchial catarrh more or less severe.

The subject of hay fever proper has been ably investigated by Dr. Blackley, whose experimental researches are generally recognised as being of the highest value, but it may be as well to point out that in those cases in which the paroxysms are indulitubly excited by the emanations from plants all kinds of pollen are not equally virulent, their activity depending on the variety of grass from which they are derived. The grasse's most productive of liay fever are the sweet-scented vernal grass (Anthoranthum orlordtum), the rye grass (Iolium perenne), and the sweet-scented soft grass (Holcus odoratus), and it is found that the fresh plant is less potent in its effect than the hay made from these grasses. Many years ago $M$. Vogel discovered that some grasses ow their odoriferous properties to the presence of benzoic acid, and it is a well-known fact that the vapour of this substance is cajulble of producing violent paroxysms of cough and sneezing, accompanied by irritation of the fauces. It is a curious circumstance, too, [1433] that amongst the Engrish branch of the Angio-Silxon race grasses are the most frequent causes of attacks of paroxysmal sneezing. whilst with Americans the pollen of the rose ind some other plants is regurded us being more potent. The frequency with which " rose fev(r," " ruse cold." or "rose" catarrh" prevails in the United Stntes is well known, whilst in India the affection is often attributed to the hlossom of the mango, which flowers in February or March, and exhales an odour not unlike that of pure terebene. In Great Britain, too, it is ly no means rare to meet with people who are affected $h y$ other pollen than that of grasses. In a case which recently came undere our notice the pullen of the common daisy (Bellis perennis) gave rise to more inconvenience than that of any other plunt. Weare told of a lady who could never remain in a room with even a single stalk of linliun corn without being seized with short ness of lireath, and on nue creision when abroad she suffered from a severe attack of asthma from groing accidentally into a room where a mattress stutfer with the leaves of Indian corn was being shaken. In another in-tanes it is recorded of a man that he could never pass the shop of a certain ropemaker in his native town withont suffering from dyspnoa, excited presumably by the dust from the flax. Cullen jeeters to the case of a mun who was seized with fits of sneezing whenever rice was threshed in the neighbourhood of the houst', whilst. Troussean tells us that he himself always had asthma if he remained for even a few minutes in a room with a bouquet of violets. The power of ipecacuanha dust to produce in certain susceptilile persons nttncks of shortness of breath has long been recongnised. Cullen relates that the wife of an apothecnry was seized with asthma whenever ipecacuanlia root was powilered in her husbands surgery even if she happened at the time ${ }^{0}$ be in anothe $r$ part of the liouse.

Sir Thomas Watson says: "I recollect a serrant employed in the laborat ory at St. Bartholomew's Hospital. when I was a pupil there, who hidel the peculiar ill-huck to be lialle to this affection. Whenever that drugr was under preparit ion he was obliged to fly the place. 'This idiosvncrasy is not very uncommon. A very small quantity of ipecacuainha dust is sufficient in such persons to bring on a paroxism of extreme dyspnoil, wheezing, and cough, with singular anxiety and great weakness. The distress usually terminates by a copious expectoration of mucus."

Some people, althourh insusceptible to the action of ipecacuanha, suffer severely from exposure to linseed or scammony. Dr. William smith, of lireston, records the case of a patient in whom a linseed-meal poultice provoked the symptoms, whilst in another instance the smell of mustard was the exciting cause. Powdered colocynth may have a similar effect, and an epidemic of sneezing. which occurred in a house was traced by us to the use of bitter apple, which was powdered over the curpets and other articles as a preventive of moth. A medical student under our care assured us that the dust from a clean pocket-handkerchief always excited in him paroxysms of sneezing, to which he was subject, and he was so nssured of this that he gave orders that his handkerchiefs should never be starchel. The coryza induced byipreparations of iodine made with methyluted spirit is well known. Fover mentions the case of a lady in whom asthmatic attacks were induced by scents of all kinds, and we are told of a sea captain engagred in the guano trade, who was so severely affected by the emanations from this substance that he had to relinquish his occupation.

Iost writers include under the term " hay fever" similar attacks induced by the exhalations from cats, dogs. horses, and other animals. Hyde Salter, in his interestinc work on Asthma, give detailed notes of sereral cises in which the short ness of breath was induced by exposure to the effluvium of various animals, his list including not only cats, dogs, and horses, but wild heasts, cattle, guinea-pigs, rablits, and hares. A patient, the proprietor of a well-known equestrinn establishment ulways had his asthma brought on by the presence of liorses, so that he was continually asthmatic. IHe had no suspicion of the real cause of his suffering till he made his fortune and retired from business, when his srmptoms departed, only to return if bs chance he visited his old haunts. Salter tells the story of a country clergyman who was always rendered asthmatic by the neighbourhood of a hare or a hareskin. If by chance he net a man who had been poaching. he at once detected him. When this gentleman was a hor studying with a private tutor, a fellow stulent, as a practical joke, put a dead hare under a sofa on which he was sitting, and he immediately liad a severe attack of his enmplaint.

Bastian, in the Philosoplical Transactions (vol. clvi. p. 583). relates some remarkable effects invariably produced on himself 
whilst working at the anatomy of the Ascaris megalocephala from the horse. These were a greatly increased secretion from the Schneiderian membrane, with irritation of it, causing continuous sneezing, also irritation of the conjunctiva, with such a sense of itchine about the eyelids and carunculne lachrymales as to make it extremely difficult to abstain from rubbing them. When they were rubbed this immediately gave rise to a swollen and puffeil condition of the eyelids, swelling of the caruncula, and extreme vascular injection of the conjunctiva, and if the rubling were at all persisted in, actual effusion of fluid would take place under the conjunctiva, raising it from the subjucent sclerotic and cornea. At the same time that these effects were produced upon the mucous membranes, the skin of the face und neck was affected so as to cause a sensation of itching somewhat similar to that which exists in mild attacks of nettli-rash.

Several cases of paroxysmal sneezing produced by emanations from animals have been under our care, und many of them serre to illustrate points of interest. The first is a typical case of sneezing produced by emanations from horses.

A gentleman, aged 24, had two cousins who suffered from asthma, and a sister who was a cat-asthmatic. His father's cousin suffered from hay fever. IIe himself, when 2.1 years old, had bronchitis, and from that time until the age of 9 liad attacks of sneezing and asthma. Ile then went to live at the seaside, and for four years was perfectly well. Little by little, however, after leaving the seaside both forms of attack recurred, sneezing first, then the asthma. For the last two years his sneezing has been growing better and his asthma worse, but he suffers more or less all the year round. He finds that either or both forms of attack may be brought on by coming near a horse, and this is the only exciting cause he can cliscover. One night at the theatre lee felt oppressed and commenced sneezing, without being able to account for it. In a few minutes, in the course of the performance, a horse galloped on the stage, and his attack then became so bad that he had to get up and leave. He found that going into a stable would at any time immediately excite a paroxysm, and that the clothes of people who had been racing had a similar effect. One day at Malton some betting men got into the same railway carriage with him, and an attack was at once induced. The emanations from horses would sometimes bring on asthma and sometimes an attack of sneezing, and not infrequently hoth. The asthma was more likely to come on in a carriage or close space, the sneezing in the open air, the attacks always lasting as long as he was exposed to the exciting cause. Flowers and grisses did not affect him in the slightest degree, but he occasionally had peptic asthma as the result of an indigestible meal. During the sneezing attacks the conjunctive and the eyeballs itched, the conjunctiva becoming red and congested. The itching was also felt over the whole of the inside? of the nose, and was frequently accompanied by irritation of the throat. The nasal cavities were examined, but nothing abnormal could be ditected. The sister's attacks, which sometimes assumed the form of sneezing and sometimes of asthma, were never excited by horses, but only by cats.

The following case of astlımn and sneezing produced by contact with a caterpillar is, we believe, unique. Some years ago we lad under our care a gentleman of neurotic temperament, who, about the age of 50 , suffered severely from acute pleurisy the result of exposure to cold and wet whilst out slooting. Ile recovered, but from that time was sulject to what he called "hairy caterpillary asthma." If by any chance he touched a caterpillar, especially a very hairy one, he was immediately seized with an attack of shortness of breath, often lasting an hour or more. Sometimes the paroxysms commenced with an attack of sneezing, accompanied by itching and irritation of the eyes and nose, with profuse watery discharge from both. He was not in the slightest degree affected by pollen, and he could pass hours in and about the stables without experiencing the slightest inconvenience. One of his daughters, who shared his temperament, was a catasthmatic, her attacks of sneezing and coryza being always induced by contact with cats, or even by the presence of one in the room. She was not subject to hay asthma, and ridiculed her father's objection to caterpillars.

The close connection existing between liay fever and intermittent sneezing is well shown in those cases where not only pollen but other excitants induce an attack.

The following is a case in point: The widow of a clergyman has suffered for many years from this complaint. She sneezes a good deal, but the running from the nose and eyes is very profuse, and out of all proportion to the sneezing. During the attack she has itching of the whole of the nose and of the ejeballs and throat. The attacks occur all the vear round, but are most severe in the summer. They often occuir the first thing in the morning, as soon us she begins to more in bed. They are excited at any time by grasses, roses, privet, and, in a less degree, by other flowers. Driving in the face of a strong wind will always bring on an at tack. Any dust, especially the dust of a helloom, brings on a violent paroxysm, and sunlight is also a frequent exciting cause. Food at once affords relief, even when no stimulant is taken, the symptoms subsiding before the meal is finished. She never catches cold in the head, and the chest is not usually affected. The attacks last from one to two hours, and nre followed by great exhaustion. She finds thut she can at once olbtain relief hy going into a dark room. It is worth mentioning that her daughters suffer from the same complaint.

This case is of interest as showing the influence of light as an exciting cause. It is a good exumple, too, of what may be called a mixed case, the attacks being induced not only by pollen, but by other causes. It may, of course, be argued that all dust is liable to contain pollen, but in this particular instance bedroom dust was found to be more likely to provokenn attack than dust from other sources. The influence of sunliglit in causing the attacks is one of the striking features of her complaint, and this is the case with many people who suffer from hay fever due to pollen. In some patients sunlight is insufficient to induce an attack unless the disease is aroused, so to sprak, hy the action of pollen, and then the rays of the sun will induce a paroxysm of sneezing, or increase its severity. In this particular hay fever is comparable with other neuroses, such as migraine and neuralgia. The complaint may be excited hy a carious tooth, and as long as this irritation persists other minor causes, such as a puff of wind on the face, will bring on a paroxy $\mathrm{sm}$; but when the predisposing cause, the decayed tooth, or whatever it may be, is removed, the minor exciting causes fail to arouse the attack. In some instances, as we all know, st rong sunlight alone is sufficient to bxirite a paroxysm of sneezing, and it is liy no means uncommon to meet with people who cunnot look at the sun without sneezing violently. We have a patient, for example who, whenever he leaves the house in the morning. if it he a fine bright day, sneezes for five or ten minutes, the attacks lesing $s($ ) violent that they often cause him to lose his train. The frequency and violence of the sneezing vary reatly in different cases, but are not uncommonly sulliciently serere to justify the patient being classed with intermittent sneezers.

The following case illustrates the influence of strong sunlight in people not afferted by pollen: $\Lambda$ boy, nged 12, suffers from attacks of cough every morning between six and eight, accompanied by wheezing and tightness of the chest. Ife has suffered in this way for two years, and during that time has been liable to colds in the head and transitory attacks of bronchitis. Strong sunlight always makes him sneeze, and causes his eyes to be "full and red," so that the tears run lown lis cheess. The sneezing is not excited by dust or pollen or by any other cause. His mother is a sneezer but not to any marked extent. Her mother suffered in the same way, and sho had two sisters who were hay-asthmatics.

J)ust, as we have scen, is a common exciting cause, its influence being attributed ly Blackley to the very general distribution of pollen. We are not able experimentally to disprove this, but we have seen so many cases where this explanntion seems to us highly improlable, that we have some hesitation in accepting it. Our difficulty is illustrated by the following case. A lady, aged 35 , or thereabouts, suffers from severe attacks of sneezing, which well nigh shake her to pieces. During a paroxrsm she is literally bent double, and suffers agonies of pain. They begin the first thing in the morning, but may attack her at other times during the day. The attacks may last only a few minutes or perhaps an hour or two; sometimes, however, they persist for twenty-four hours, or even three or four days. The sneezing is accompanied hy profuse watery rumning from the eyes and nose, and the eyes become red and swollen. She soaks her pocket-handkerchiefs throngh and through, and her washing bill is a heary one. 'I'he attack is always preceded by "pins and needles" over both nasal bones, the frontal sinus and the upper eyelicl, with itching of the tip of the nose. but without any itching of the nostrils or irritation of the throat. The itching not uncommonly occurs without the sneezing, but the sneering never 
without the itching and the sensations of "pins and needles." House dust will bring on an attack, bedroom dust and the dust from shaking a bed being most potent. The dust of the street, curiously enough, does not affect her; indeed, she often experiences relief during a paroxysm from going out of doors. Flowers do not bring on the attacks, which cannot be due to hay, for she resides in a large city; they occur at all times of the year. Sunlight will not excite the attack, although she complains that it hurts her eyes. She obtuins some relief from taking food, hot tea, or port wine. IIer mother has been a sneezer all her life.

$\Lambda$ middle-aged man, an ironmonger, has suffered from paroxysmal coryza and usthma for two years, the attacks being induced only by the dust of his shop. Other kinds of dust, for example that of a road, fail to affect him, and flowers, grasses, and bright sunlight are innocuous. The case is peculiar in this respect, that whilst coryza and asthma are excited only by the dust of his shop, he in certain localities suffers at night from simple asthma without coryza.

Sneezing may sometimes be induced by violent exercise. A patient, who has been a sneezer for twelre years, assures us that in his case this is the most powerful exciting cause, and he always suffers severely if he takes a long ride on his bicycle. The sneezing generally lasts half an hour or more, and is accompanied by profuse watery nasal discharge. When the exercise taken is unusually violent, the nose swells about the bridge, and the conjunctive become red and irritable. He does not suffer from itching of the nose or any part of the fuce. The attacks are never excited by dust, and he is not affected in any way by smoke, hay, or the smell of flowers. He has occasionally had an attack in the middle of the night, for which he can assign no cause. These night attacks, however, have ceased since he has worn a nightcap. Two years ago he becnme the subject of peptic asthma, and more recently caught cold, which brought on an attack of bronchitic asthma. The asthmatic attacks usually commence about two or three o'clock in the morning, and terminate with a sharp paroxysm of sneezing. IIis father was asthmatic, but has outgrown it.

Food is sometimes assigned as the exciting cause of attacks of sneezing. 1 nervous man subject to attacks of neuralgia stated that for nearly two years he had suffered from sneezing after meals, and especially after breakfast and linner. The occurrence of these attacks was favoured by excitement, nervous fatigue, or brain work. He of ten wakes up with a migrainous heallache over the left brow or at the back of the head, and then immediately after breakfast sneezes violently twenty or thirty times, the attack being accompanied by cough and expectoration, and running at the nose and eyes. IIle has never been able to discover any other cause for the attacks except food. It is probable that in this case the affection is central in origin. We assume that an impression conreyed from the stomach through the ragus and reaching its centre would, through diminished resistance in this part of the central nervous system, spread thence to that part of the fifth nucleus in connection with the nerves proceeding from the mucous membrane of the nose, inducing in this part of the nervous centre those molecular changes which impress on the sensorium the sensation of tingling or pricking, and this condition of the nervous centre of the fifth excites violent sneezing.

From these cases it will be seen that the exciting causes of attacks of sneezing are various, the chief being pollen, the emanations from rarious animals, and bright sunlight. In some instances it is difficult or impossible to discover any exciting cause, as is often the case in the allied affections-asthma, neuralgia, and migraine. In these cases the mucous membranes may be perfectly healthy, or there may be slight chronic catarrh of the nose.

The following case illustrates the power of this nasal irritation to intensify the attacks: The patient, a gentleman aged 45 , has been subject to neuralgia for many years. IIe has had attacks of persistent sneezing for three months. They may occur at any time of the day, lut are usually worse after dinner. II has constant tingling in the left nostril posteriorly, and in the region of the septum. At times this pain becomes much worse, and radiates over a large area, reaching the ala of the left nostril. This "sliarp pang," as he terms it, excites the attacks of sneezing. There is a constant watery discharge, but this is intensified during the sneezing attacks. The discharte is worse from the nostril which itches. IIe is quite unalle to discover any exciting cause, but is satisfied that it is not dust or pollen or bright light.

$\Delta$ lady, aged 70 , has almost every night for years had attaclis, lasting from twenty minutes to an hour, beginning with itching behind the sternum, and leading to a severe paroxysmal cough, accompanied by profuse running from the eyes and nose without itching of the nostrils or eyes, and with only an occasional paroxysm of sneezing. This case is of interest from its affinity with asthma.

Asthma, as we know, often changes its character, and may be replaced by paroxysmal cough or dyspnoca. Many patients suffer from itching over the sternum, which precedes the attack. We know, too, that many diseases in their transmission from parent to child change their type; an epileptic parent, for example, begetting a neuralgic, migrainous, or rheumatic child, or several members of the family may have different neuroses. In other words, these same changes in the nervous system in transmission affect probably a different part of the central nervous system, and so induce a different set of symptoms. We know too that in the same individual one neurosis may replace another, and this interchange may occur not once lut niany times. In other cases two or more neuroses not only affect the same person, but the attacks may occur simultaneously, a fact well illustrated by the following case.

A little girl, aged 6, has had chronic Bright's disease for some years, but she is now nearly well, although a little cystitis remains. Every week, or sometimes of tener, she has attacks of running from the eyes, the lids becoming swollen, the upper especially, and the conjunctive suffused and bloodshot. The right eye is always more affected than the left, the difference being well marked. There is great intolerance of light, so that the room has to be darkened, and usually she keeps her eyes covered with a shade. The nose runs, but she seldom sneezes. The bowels invariably act at the onset of the attack, the motions being light in colour. She always romits about half an hour after the commencement of the attack, and ejects a large qunntity of bilious matter. The tongue is red and spotty, and frequently covered with circular pat ches like raw beef-steak. There is no shortness of breath, but the attack is followed by drowsiness. The only cause that can be discovered is excitement, but often enough the attacks come on when the patient has been kept quiet. It is thought that inattention to diet will intensify them and prolong their duration, but on this point the evidence is not clear.

\section{THREE LECTURES \\ TUBERCULAR JOINT-DISEASE AND ITS TREATMENT BY OPERATION.}

Delivered at the Royal College of Surgeons of England, June, 1888.

BY ARTIIUR E. J. BARKER, F.R.C.S.,

Irunterian Professor of Surgery and Patholouy at the Royal College of
Surgeons; Surreon to University College Hospital; and Teacher of Practical Surgery at University College.

LECTIRA II.

Is the light of the researches and deductions briefly alluded to in my last lecture, we have now to consider the behaviour of tubercular disease in the joints. That this is identically the same affection as that known under the same name in the lungs and other organs, there can, as I have shown, be no manner of doubt ; and that the presence of the bacillus tuberculosis is associated with analogous tissue clianges in the joints to those found in the interna? organs, is also, I think, beyond dispute. But why the structures entering into the composition of the articulations are so liable to be infected, as appears to be the case, is one aspect of the question which claims a short notice.

In the first place, it is almost certain that here we are dealing with a secondary infection in the rast majority of cases; in other words, that the organism introluced into the system elsewhere and present in the blood has found, in its wanderings, a home peculiarly fitted for its growth in the tissues of the joint. That direct infection of the latter may take place through a wound has been shown more than once, notably by such cases as those recorded by Pfeiffer and Middeldorpf; but this must be such an exceptional occurrence as hardly to need consideration.

In spenking of infection of the joints it will, of course, be understood that only the synovial structures and the cancellous tissue of the bone's are referred to. In these alone does the dis- 